\title{
Activity restriction in mild COPD: a challenging clinical problem
}

This article was published in the following Dove Press journal:

International Journal of COPD

4 June 2014

Number of times this article has been viewed

\section{Denis E O'Donnell' \\ Kevin B Gebke² \\ 'Division of Respiratory and Critical Care Medicine, Respiratory Investigation Unit, Queen's University and Kingston General Hospital, Kingston, ON, Canada; ${ }^{2}$ Primary Care Sports Medicine Program, Indiana University School of Medicine, Indianapolis, IN, USA}

Abstract: Dyspnea, exercise intolerance, and activity restriction are already apparent in mild chronic obstructive pulmonary disease (COPD). However, patients may not seek medical help until their symptoms become troublesome and persistent and significant respiratory impairment is already present; as a consequence, further sustained physical inactivity may contribute to disease progression. Ventilatory and gas exchange impairment, cardiac dysfunction, and skeletal muscle dysfunction are present to a variable degree in patients with mild COPD, and collectively may contribute to exercise intolerance. As such, there is increasing interest in evaluating exercise tolerance and physical activity in symptomatic patients with COPD who have mild airway obstruction, as defined by spirometry. Simple questionnaires, eg, the modified British Medical Research Council dyspnea scale and the COPD Assessment Test, or exercise tests, eg, the 6-minute or incremental and endurance exercise tests can be used to assess exercise performance and functional status. Pedometers and accelerometers are used to evaluate physical activity, and endurance tests (cycle or treadmill) using constant work rate protocols are used to assess the effects of interventions such as pulmonary rehabilitation. In addition, alternative outcome measurements, such as tests of small airway dysfunction and laboratory-based exercise tests, are used to measure the extent of physiological impairment in individuals with persistent dyspnea. This review describes the mechanisms of exercise limitation in patients with mild COPD and the interventions that can potentially improve exercise tolerance. Also discussed are the benefits of pulmonary rehabilitation and the potential role of pharmacologic treatment in symptomatic patients with mild COPD.

Keywords: chronic obstructive pulmonary disease (COPD), small airway dysfunction, dyspnea, physical activity, exercise

\section{Introduction}

Chronic obstructive pulmonary disease (COPD) is a common, preventable, and treatable disease, characterized by chronic inflammation of the airways and lungs, persistent airflow limitation, and, in many, a progressive decline in lung function. It is associated with significant morbidity and increased mortality, ${ }^{1,2}$ even in patients with mild airflow obstruction. Despite this prospect, the disease often goes undiagnosed and untreated until it has progressed to a point where lung function and quality of life are severely compromised.,

The clinical expression of COPD in its early phase of development depends on the integration of several factors, which include: the nature and extent of the physiological impairment; the compensatory responses mobilized to maintain effective pulmonary gas exchange; and the subjective behavioral response to encroachment of 
the respiratory reserve (eg, activity avoidance) (Figure 1). In the current review, the main focus is on smokers with apparently mild airway obstruction but who report persistent activity-related dyspnea.

Physical inactivity is often the consequence of troublesome dyspnea and is considered to be a major contributor to the progression of COPD, which, in turn, has been associated with the development of comorbidities, increased risk for hospitalization and associated health care costs, and increased rates of mortality. ${ }^{5,6}$ Physical inactivity is also considered by some to cause systemic inflammation, which leads to development of comorbidities, such as COPD. ${ }^{7,8}$ By contrast, regular physical activity is known to reduce rates of hospitalization and all-cause and respiratory mortality in patients with COPD, ${ }^{6,9}$ although the impact of physical activity in mild disease is less well understood.

In the past, there has been a perception that mild airway obstruction, as defined by spirometry (ie, post-bronchodilator forced expiratory flow in 1 second $\left[\mathrm{FEV}_{1}\right] /$ forced vital capacity $<0.7$ and $\mathrm{FEV}_{1}>80 \%$ predicted), has few clinical consequences and does not require intervention. ${ }^{10}$ However, there is mounting evidence that mild airflow obstruction is associated with a reduction in exercise capacity in patients with COPD. ${ }^{5,11,12}$ Even before patients are aware of their illness, they often habitually restrict some of their more strenuous activities to avoid unpleasant symptoms, such as dyspnea. Over time, this can lead to a spiral of worsening symptoms, deconditioning, and exercise intolerance as patients become progressively more sedentary, ${ }^{13}$ and provides a compelling rationale for consideration of early intervention.

Smoking cessation is the pivotal and most effective intervention in patients with COPD. ${ }^{14,15}$ It is also well established that pharmacologic treatment, together with nonpharmacologic interventions, can effectively reduce the intensity of dyspnea and improve exercise capacity in moderate-tosevere COPD, ${ }^{1,16,17}$ although this is not well documented in mild disease.

This review summarizes the importance and benefits of encouraging physical activity and exercise in mild COPD, with a focus on alternative outcome measurements, such as small airway dysfunction and exercise abnormalities, which are already apparent in the mild stage of the disease..$^{10,11,18,19}$ Also discussed are the potential benefits for patients with mild COPD of smoking cessation, regular physical activity, and pulmonary rehabilitation (PR), in combination with pharmacologic treatment, which have already been shown to improve dyspnea, quality of life, exercise endurance, and functional capacity of patients with more advanced disease. ${ }^{20}$

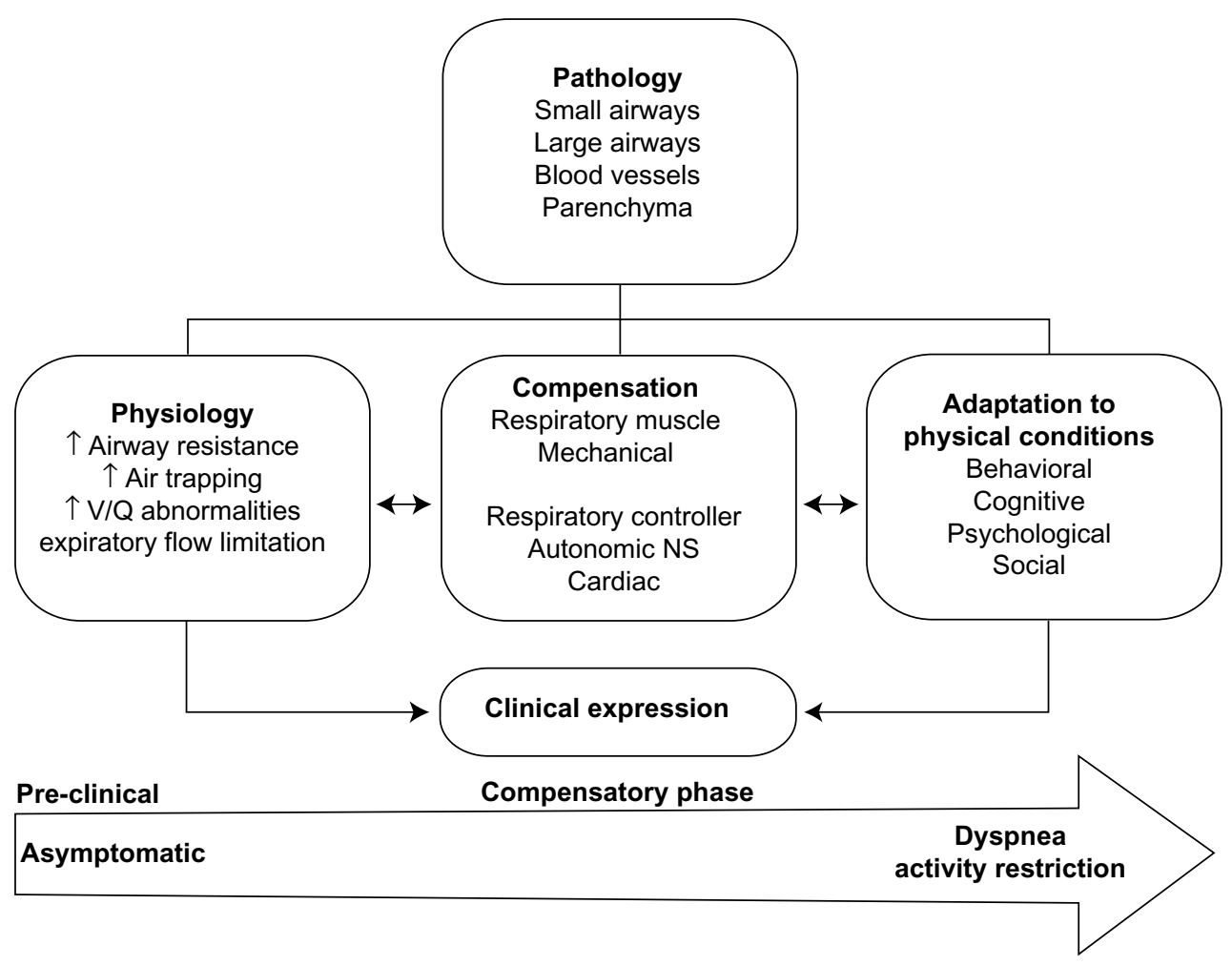

Figure I Characterization of mild chronic obstructive pulmonary disease. Abbreviations: NS, nervous system; V/Q, ventilation/perfusion. 


\section{Exercise abnormalities in COPD}

Exercise and activity limitation are already apparent in patients at the mild stage of COPD (Global initiative for chronic Obstructive Lung Disease [GOLD] 1), ${ }^{1,10,11,18}$ with exercise tolerance becoming increasingly compromised with disease progression. ${ }^{5,21}$ Exertional dyspnea and leg discomfort are common exercise-limiting symptoms in patients with COPD, including symptomatic patients with mild airflow obstruction. ${ }^{11,18}$ Both symptoms result from a complex interaction of factors, such as baseline respiratory mechanical dysfunction, ${ }^{22}$ individual susceptibility to leg muscle fatigue, ${ }^{23}$ type of exercise, ${ }^{24-26}$ and bronchodilation status, ${ }^{27-29}$ the consequences of which vary from patient to patient. As dyspnea and leg fatigue worsen, the patient leads a more sedentary lifestyle in order to avoid these symptoms, resulting in skeletal muscle deconditioning, exercise intolerance, and poor quality of life. ${ }^{13}$

\section{Mechanisms of exercise limitation in mild symptomatic COPD}

Patients with mild COPD exhibit a diverse range of structural abnormalities of the lungs and airways, including airway wall thickening, pulmonary gas trapping, emphysema, and vascular dysfunction. ${ }^{30-32}$ As a result, these patients display substantial heterogeneity in airways resistance and conductance, pulmonary gas trapping, resting (static) lung hyperinflation, and integrity of the alveolar-capillary gas exchange interface. ${ }^{33}$ Recent evidence has also shown that dynamic hyperinflation (during exercise) occurs in many patients with mild COPD, independently of whether patients have resting hyperinflation. ${ }^{34}$ Understanding the structurefunction relationships in the lungs and airways may assist understanding of exercise limitations in COPD.

\section{Small airway dysfunction}

The small airways, ie, those $<2 \mathrm{~mm}$ in diameter, are the major sites of obstruction in patients with COPD. ${ }^{35}$ Narrowing, occlusion, and loss of small airways have been confirmed from resected lung specimens, even in patients with mild COPD, using quantitative computed tomography, ${ }^{19,35,36}$ and are associated with enhanced inflammatory and repair responses, as well as a build-up of inflammatory mucus exudates in some patients. ${ }^{36}$ Recent findings suggest that these changes precede the onset of centrilobular emphysema. ${ }^{19}$

Persistent expiratory flow limitation (EFL) is the defining feature of COPD. It occurs when expiratory flow cannot be increased because it is already at maximum during spontaneous tidal breathing at that lung volume. EFL arises due to the combined effects of airway narrowing, diminished lung elastic recoil, airway-parenchyma uncoupling, and dynamic airway collapse. ${ }^{37-39}$ The relative contribution of each of these factors to EFL in patients with mild COPD varies from patient to patient and is difficult to quantify conclusively. ${ }^{38,40}$

\section{Ventilation/perfusion $\left(\mathrm{V}_{\mathrm{A}} / \mathrm{Q}\right)$ abnormalities}

Patients with mild-to-moderate COPD commonly exhibit abnormal $\mathrm{V}_{\mathrm{A}} / \mathrm{Q}$ mismatch while breathing at rest, despite a largely preserved $\mathrm{FEV}_{1}{ }^{41-43}$ Resting alveolar-to-arterial oxygen tension gradient has been shown to be abnormally widened $(>15 \mathrm{mmHg})$ in patients with mild-to-moderate COPD who have regional low $\mathrm{V}_{\mathrm{A}} / \mathrm{Q}$ ratios. ${ }^{41,42}$ In patients with emphysematous destruction, high $\mathrm{V}_{\mathrm{A}} / \mathrm{Q}$ ratios (and wasted ventilation) may be dominant. Such patients exhibit a decreased surface area for gas exchange, as evidenced by a reduced diffusing capacity of the lung for carbon monoxide, and small vessel disease, both of which have been demonstrated in patients with mild COPD.,.$^{30,41-44}$ These abnormalities likely contribute to a higher ventilatory requirement during exercise in patients with mild COPD (Figure 2).

\section{Responses to exercise in mild COPD High ventilatory demand}

Peak oxygen consumption $\left(\mathrm{V}^{\prime} \mathrm{O}_{2}\right)$ and minute ventilation $\left(\mathrm{V}_{\mathrm{E}}^{\prime}\right)$ are reduced, and perceived dyspnea is increased during incremental exercise to tolerance in patients with mild COPD compared with healthy controls. ${ }^{10,11,18,45,46}$ By contrast, ventilatory equivalent for carbon dioxide $\left(\mathrm{V}_{\mathrm{E}}^{\prime}, \mathrm{V}^{\prime} \mathrm{CO}_{2}\right)$ output is consistently higher during cycle ${ }^{10,11,18}$ and treadmill exercise test ${ }^{46}$ in this patient population. This abnormality may reflect an impaired ability to reduce higher physiologic dead space during exercise in patients with mild COPD, an altered set-point for arterial partial pressure of carbon dioxide, or a combination of the two. However, significant arterial $\mathrm{O}_{2}$ desaturation $(>5 \%)$ has not been reported during incremental cycle exercise, ${ }^{10,11,18,45}$ suggesting that compensatory increases in $\mathrm{V}_{\mathrm{E}}$, and normal increase in cardiac output, ensure an improved $\mathrm{V}_{\mathrm{A}} / \mathrm{Q}$ relationship during exercise in these patients..$^{41,42,47}$ In some patients, earlier metabolic acidosis, as a result of skeletal muscle deconditioning, provides an added stimulus to $\mathrm{V}_{\mathrm{E}}$, during exercise. ${ }^{11,18}$

\section{Impairment of dynamic respiratory mechanics}

In addition to higher ventilatory requirements, dynamic gas trapping and mechanical constraints on tidal volume $\left(\mathrm{V}_{\mathrm{T}}\right)$ expansion may contribute to reduced peak $\mathrm{V}^{\prime} \mathrm{O}_{2}$ and $\mathrm{V}_{\mathrm{E}}{ }_{\mathrm{E}}$ in patients with mild COPD. ${ }^{10,11,18,45}$ Exercise-induced gas trapping occurs through a combination of tachypnea 

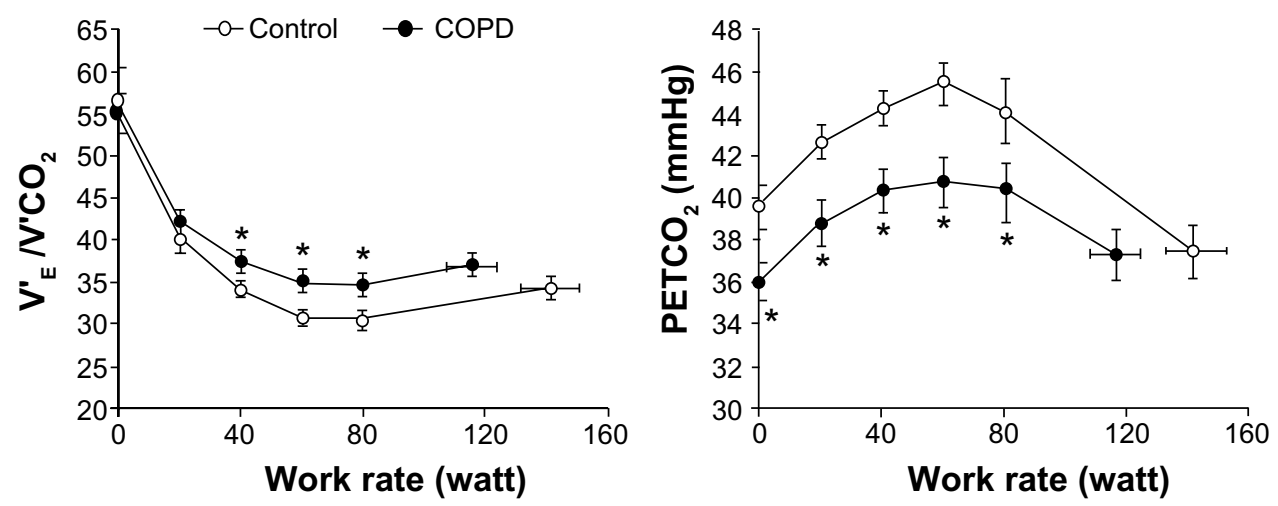

$$
\mathrm{V}_{\mathrm{E}}^{\prime} \mathrm{N}^{\prime} \mathrm{CO}_{2}=\frac{863}{\mathrm{PaCO}_{2} \times\left(1-\mathrm{V}_{\mathrm{D}} / \mathrm{V}_{\mathrm{T}}\right)}
$$

Figure 2 Ventilatory insufficiency in mild chronic obstructive pulmonary disease. $\mathrm{V}_{\mathrm{E}}^{\prime} / \mathrm{V}^{\prime} \mathrm{CO}_{2}$ (left) and $\mathrm{PETCO}_{2}$ (right) in response to symptom-limited incremental cycle exercise in patients with mild COPD and healthy controls (Mean $\pm \mathrm{SE}$ ) at rest, 20, 40, 60, and 80 watt during exercise and at peak exercise $(* P<0.05)$ COPD versus control at a standardized work rate (watt).

Reprinted with permission of the American Thoracic Society. Copyright (c) 2013 American Thoracic Society. Ofir D, Laveneziana P, Webb KA, Lam YM, O’Donnell DE. Mechanisms of dyspnea during cycle exercise in symptomatic patients with GOLD stage I chronic obstructive pulmonary disease. Am J Respir Crit Care Med. 2008; I77(6):622-629. Official Journal of the American Thoracic Society."

Abbreviations: $\mathrm{V}_{\mathrm{E}}^{\prime}$, minute ventilation; $\mathrm{V}_{\mathrm{E}}^{\prime} \mathrm{N}^{\prime} \mathrm{CO}_{2}$, ventilatory equivalent for carbon dioxide; $\mathrm{PETCO}$, partial pressure of end-tidal carbon dioxide; $\mathrm{PaCO}$, arterial partial pressure of carbon dioxide; VD, dead space volume; $\mathrm{VT}$, tidal volume; $\mathrm{V}^{\prime} \mathrm{CO}_{2}$, carbon dioxide output; COPD, chronic obstructive pulmonary disease.

and EFL: end-expiratory lung volume (EELV) increases and inspiratory capacity decreases (Figure 3), which is reflected in the dyspnea slope that was significantly $(P<0.05)$ steeper in patients with GOLD 1 COPD compared with normal healthy controls (Figure 4). ${ }^{11}$ Thus, expiratory time becomes insufficient to allow EELV to decline to its natural relaxation volume between breaths and becomes dynamically (rather than statically) determined.

EELV

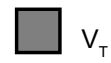

$V_{T} \square I R V$

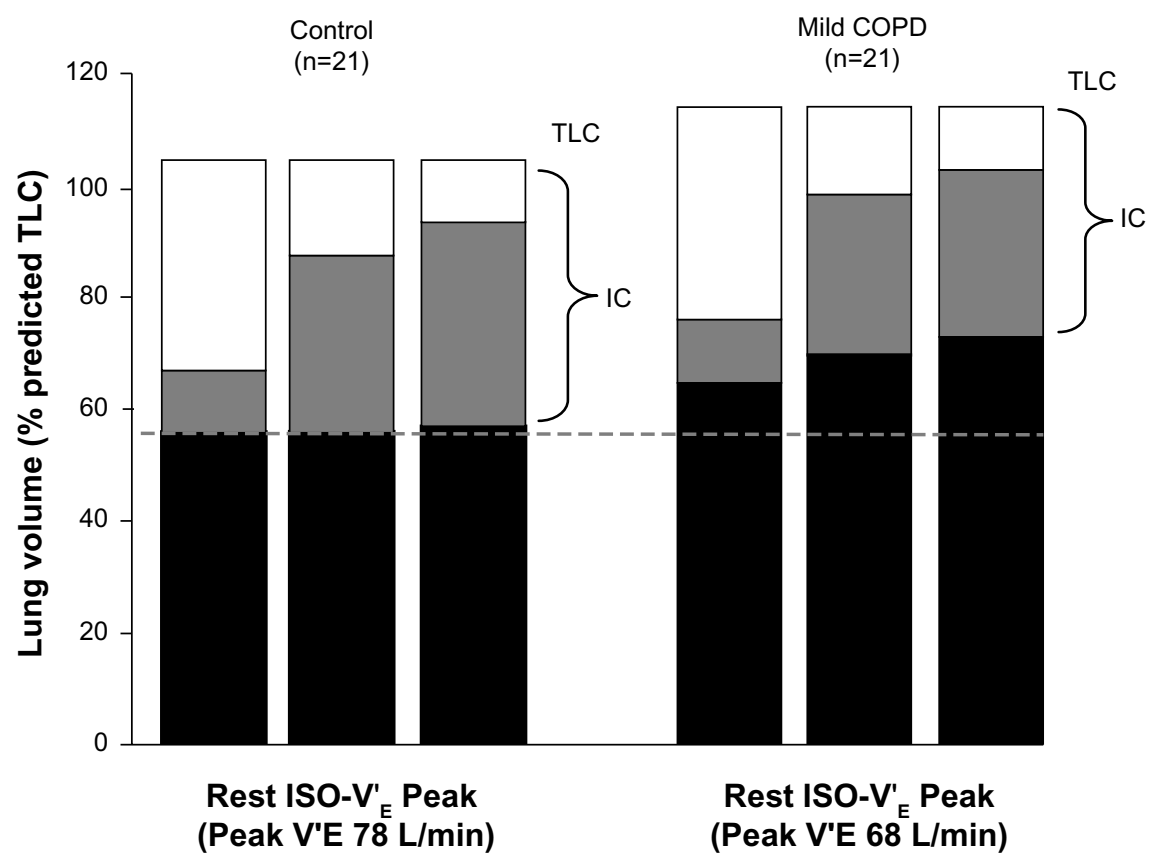

Figure 3 Operating lung volumes during exercise.

Note: Data from Ofir D, Laveneziana P, Webb KA, Lam YM, O'Donnell DE. Mechanisms of dyspnea during cycle exercise in symptomatic patients with GOLD stage I chronic obstructive pulmonary disease. Am J Respir Crit Care Med. 2008;177(6):622-629. Official Journal of the American Thoracic Society. ${ }^{11}$

Abbreviations: COPD, chronic obstructive pulmonary disease; EELV, end-expiratory lung volume; IC, inspiratory capacity; IRV, inspiratory reserve volume; ISO-V' ${ }_{\mathrm{E}}$, isotime minute ventilation; TLC, total lung capacity; VT, tidal volume. 
$\multimap$ GOLD I mild $(n=21) —$ Normal $(n=21)$

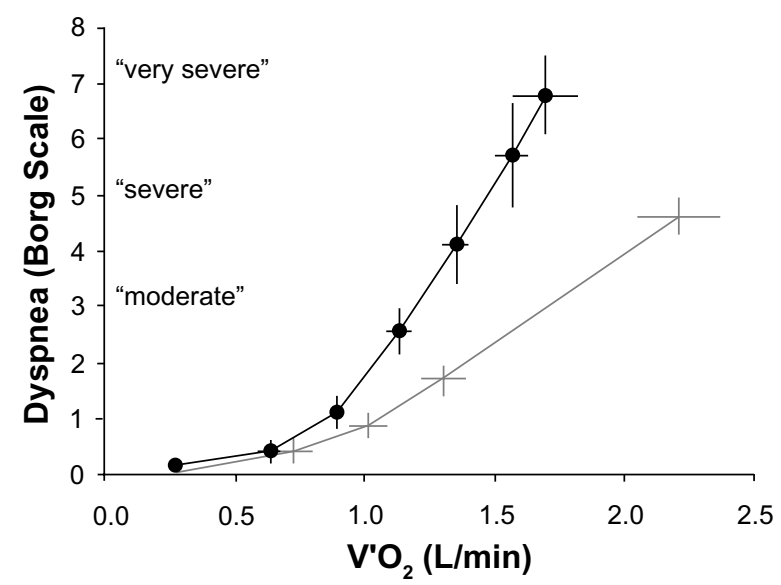

Figure 4 Exertional dyspnea intensity

Notes: Values are means \pm standard error of the mean. Mild $>$ normal slopes $(P<0.05)$ Adapted with permission of the American Thoracic Society. Copyright (C) 2013 American Thoracic Society. Ofir D, Laveneziana P,Webb KA, Lam YM, O’Donnell DE. Mechanisms of dyspnea during cycle exercise in symptomatic patients with GOLD stage I chronic obstructive pulmonary disease. Am J Respir Crit Care Med. 2008; I77(6): 622-629. Official Journal of the American Thoracic Society; " Borg Scale. ${ }^{48}$

Abbreviations: GOLD, Global initiative for chronic Obstructive Lung Disease; $\mathrm{V}^{\prime} \mathrm{O}_{2}$, oxygen consumption.

Previous studies in healthy individuals have shown that selective stressing of the respiratory system, by adding dead space to the breathing apparatus, results in significant increases in peak $\mathrm{V}_{\mathrm{T}}$ and $\mathrm{V}_{\mathrm{E}}$, and a preservation of exercise capacity. ${ }^{49-51}$ By contrast, the ability of patients with advanced COPD to increase $\mathrm{V}_{\mathrm{E}}^{\prime}$ in response to such added chemostimulation is markedly diminished, ${ }^{52}$ and suggests that impaired respiratory mechanics represent the proximate limitation to exercise in COPD. These findings were recently extended to patients with mild COPD.$^{18}$ In this latter group, an inability to further increase end-inspiratory lung volume, $\mathrm{V}_{\mathrm{T}}$, and $\mathrm{V}_{\mathrm{E}}{ }_{\mathrm{E}}$ at the peak of exercise in response to dead space loading indicated that the respiratory system had reached its physiological limits at the end of exercise. Moreover, this abnormality occurred in a setting of adequate cardiac reserve. Such critical mechanical constraints on $\mathrm{V}_{\mathrm{T}}$ expansion during added dead space breathing were associated with an earlier onset of intolerable dyspnea in patients with mild COPD but not in healthy controls. ${ }^{18}$

Mechanical studies have also confirmed that dynamic lung compliance is decreased and pulmonary resistance, restto-peak changes in EELV, intrinsic positive end-expiratory pressures, and oxygen cost and work of breathing are increased in symptomatic patients with mild COPD compared with healthy controls. ${ }^{11,45}$

\section{Cardiocirculatory impairment}

As smoking history is a common risk factor for both COPD and cardiovascular disease, it is not surprising that patients with COPD display a range of cardiocirculatory abnormalities. Historically, it was widely believed that cardiovascular complications occurred only in patients with advanced disease as a consequence of chronic hypoxemia, eg, pulmonary hypertension and cor pulmonale. More recently, however, it is recognized that cardiovascular dysfunction is a common comorbidity in mild-to-moderate COPD. ${ }^{53-59}$

In a large Danish population study, the presence of dyspnea and mild airway obstruction was shown to be an independent predictor of cardiovascular mortality. ${ }^{60}$ Preclinical, mild airflow obstruction is associated with smaller left ventricular enddiastolic volumes and decrements in stroke volume and cardiac output. ${ }^{53,54}$ Minor, increased emphysema is also associated with impaired left ventricular diastolic function and reduced cardiac output. ${ }^{54,55}$ Emphysematous destruction of lung parenchyma and pulmonary capillary beds, endothelial dysfunction, reduced pulmonary blood flow, and increased pulmonary vascular resistance have been suggested as possible underlying mechanisms responsible for these abnormalities..$^{53,54}$

\section{Skeletal muscle dysfunction}

Activity limitation inevitably leads to deconditioning and skeletal muscle dysfunction, manifested as marked declines in muscle mass and strength, which contribute to impaired mobility, poor health status, and further exercise intolerance. ${ }^{1,61}$ There is a growing appreciation that structural and functional abnormalities of the skeletal muscles can develop in patients with mild COPD. ${ }^{62-65}$ Skeletal muscle impairment may, in turn, lead to reduced exercise capacity. ${ }^{12}$ Muscle injury, ${ }^{62}$ loss of skeletal muscle oxidative capacity, and diminished endurance ${ }^{63}$ have been reported in patients with mild-to-moderate COPD and appear to develop in the absence of significant muscle wasting. ${ }^{12}$

Physical inactivity and deconditioning are thought to contribute to skeletal muscle dysfunction, and the initiation of exercise training programs has been shown to improve muscle function; ${ }^{66}$ however, physical inactivity is not thought to be the sole determinant of muscle impairment in mild-tomoderate COPD ${ }^{63}$ Muscle impairment worsens with progressive lung function, suggesting the involvement of oxidative stress. ${ }^{63}$ Active smoking may also play a significant role due to its negative impact on muscle bioenergetics and protein synthesis. ${ }^{63}$

\section{Assessment of exercise tolerance}

Due to the detrimental role of physical inactivity in COPD, a complete patient assessment should include both assessment of usual activity levels and measurement of lung function. Clinical trials of interventions for COPD frequently 
assess physical activity using either subjective methods, including patient diaries and questionnaires, ${ }^{67}$ or objective methods, eg, pedometers ${ }^{68}$ or accelerometers. ${ }^{67}$ Subjective methods are inexpensive, easy to administer, and represent the patients' perspective on their functional status. A wide variety of simple questionnaires for quantifying physical activity has been reviewed. ${ }^{67}$ These methods do have their limitations, such as the potential for erroneous reporting, recall bias, and interpretation issues. ${ }^{69}$

Simple assessment of physical activity and symptoms may help reveal the impact of COPD on patients' daily lives. Pedometers count the number of steps taken by detecting vertical movements, but can underestimate slow walking, such as in elderly patients, ${ }^{70}$ and provide no information about the time spent in individual activities or the intensity of the activities performed. ${ }^{67}$ Accelerometers are more technologically advanced than pedometers, and multiaxial devices are able to detect movement in multiple planes of motion. ${ }^{71}$ Unlike pedometers, accelerometers are also generally capable of recording and storing information on exercise intensity. Newer devices, incorporating multiaxial accelerometers and multiple physiological sensors, are able to estimate energy expenditure even at the slow walking pace typical of elderly patients with COPD. ${ }^{72,73}$ The significance of assessing physical activity was demonstrated in a recent study, which found that all-cause mortality in patients with COPD was best predicted using objective measures of physical activity. ${ }^{74}$

Endurance tests using constant work rate (CWR) protocols, ie, cycle ergometer or treadmill, are often used to assess the effects of PR because exercise training has little effect on maximal exercise capacity but can improve endurance. ${ }^{75}$ Furthermore, CWR protocols are gaining popularity because they are able to assess improvements in endurance as a result of $\mathrm{PR}^{75}$ and are responsive to the beneficial effects of bronchodilators on symptoms that limit exercise tolerance. ${ }^{45,76-79}$

\section{Simple assessment of physical activity}

Simple assessment of physical activity in patients with COPD is by the use of tools or questionnaires designed to assess a patient's ability to accomplish basic and instrumental activities of daily living, ${ }^{80}$ eg, the well-established London Chest Activity of Daily Living scale (LCADL), which assesses dyspnea during a patient's activities. ${ }^{81}$ Interestingly, a recent systematic review has concluded that assessment of activities of daily living should be used more often as a clinical outcome in the management of patients with COPD. ${ }^{82}$

The modified British Medical Research Council (mMRC) dyspnea scale ${ }^{83}$ and the COPD Assessment Test (CATC) 2009;
GlaxoSmithKline, Brentford, UK) ${ }^{84}$ are used by the GOLD guidelines for symptom/risk evaluation. ${ }^{1}$ Together, these questionnaires represent valuable tools for pulmonologists that can help to provide a clear assessment of an individual's disease severity. The mMRC dyspnea scale uses a simple grading system to assess a patient's level of dyspnea from 0 (only breathless with strenuous exercise) to 4 (too breathless to leave the house or breathless when dressing). ${ }^{83}$ The majority of patients with mild ( $\mathrm{FEV}_{1}>80 \%$ predicted) airflow obstruction provide a score of $0-1$ on the mMRC dyspnea scale..$^{12,85}$ The mMRC dyspnea scale is also used to help calculate the dyspnea arm of the BODE Index: body mass index (B), airflow obstruction (O), dyspnea (D), and exercise tolerance (E), ${ }^{86}$ which is used to predict mortality in COPD. Validation of the BODE Index has shown that a BODE score of 3-4 and mildto-moderate airflow limitation $\left(\mathrm{FEV}_{1}>50 \%\right)$ are associated with a similar survival probability $(\sim 0.7) .{ }^{87}$

The CAT is a questionnaire used to measure the overall impact of COPD on a patient's life. It consists of eight items, each scored 0 (no impact) to 5 (very severe impact), giving a total score range of $0-40$, where a higher CAT score indicates that COPD is having a more severe impact on a patient's life. In a recent European cross-sectional study, Jones et $\mathrm{al}^{85}$ proposed that a CAT score $\geq 10$ is clinically meaningful, and showed that patients with mild airflow obstruction already display significant health status impairment (CAT score $~ 16$ ). While the total CAT score does not provide a specific evaluation of dyspnea and activity limitation, it can help to identify patients in whom these two symptoms are perceived as problematic.

\section{6-minute walking distance test (6MWT)}

The 6MWT is a practical method of assessing exercise tolerance and tracking functional changes in patients with COPD. Requiring little more than a 100-foot hallway and a stopwatch, the 6MWT measures the distance that a patient can walk on a flat, hard surface over 6 minutes. In contrast to tests that focus on a single component of physical function, the 6MWT evaluates the integrated response of pulmonary, cardiovascular, and muscular components.

Because the 6MWT is self-paced and dependent on patient motivation, the test measures submaximal exercise tolerance rather than exercise capacity. ${ }^{88}$ However, because most activities are performed at submaximal levels, the 6MWT is believed to provide useful information regarding activities of daily living, in that patients with a severely impaired 6-minute walking distance are likely to have very low physical activity levels in daily life. ${ }^{21}$ It is also better tolerated than other walking tests. ${ }^{89}$ 
Results of the 6MWT have been correlated with health status, dyspnea at rest, maximum exercise capacity, and mortality. ${ }^{90-92}$ The 6MWT distance speed is generally similar between patients with mild COPD and healthy controls. ${ }^{93}$ However, Díaz et $a^{12}$ recently showed that the 6MWT distance is significantly reduced in dyspneic patients with mild COPD, compared with non-dyspneic patients and smoker controls.

\section{Incremental (ISWT) and endurance (ESWT) shuttle walking tests}

Similar to the 6MWT, the ISWT is a field-based walking test, which does not require expensive equipment. However, unlike the 6MWT, the ISWT is externally paced and walking speed is incrementally increased each minute until the patient is limited by symptoms. The ISWT was developed to provide a field-based equivalent of the more advanced laboratory-based tests that measure peak exercise capacity. ${ }^{94,95} \mathrm{~A}$ variation of the ISWT, the ESWT is conducted at a constant pace $(80 \%-85 \%$ of peak effort based on a prior ISWT) and continues until the patient is limited by symptoms. ${ }^{96} \mathrm{~A}$ number of studies have demonstrated that the ESWT is responsive to the effects of bronchodilators on exercise tolerance ${ }^{26,97,98}$ and may have better discriminative properties than the 6MWT.97

There is a paucity of studies that have evaluated ISWT and ESWT in patients with mild COPD. In one small study, Boer et a ${ }^{99}$ suggest that there is no significant difference in ISWT distance between patients with mild COPD and smoker controls, despite a significant difference between patients with moderate COPD and smoker controls.

\section{Laboratory cardiopulmonary exercise testing}

Although laboratory tests of exercise performance are not widely available, they can be very useful in evaluating the nature and extent of physiological impairment on an individual basis and can help in the planning of personalized treatment. Incremental cycle and treadmill tests represent the gold standard for the evaluation of integrated physiological responses to the stress of physical activity. These tests are particularly valuable for the investigation of disproportionate dyspnea and/or unexplained exercise intolerance in patients with mild airway obstruction. Consistent abnormalities in mild COPD include: increased dyspnea and leg discomfort ratings (as measured using the Borg Scale ${ }^{48}$ ); decreased peak oxygen uptake and work rate; increased ventilatory inefficiency; increased gas trapping (as measured by serial inspiratory capacity measurements); and a relatively rapid shallow breathing pattern with an early plateau of $\mathrm{V}_{\mathrm{T}^{0}}{ }^{10,11,18,45,100}$
In some patients, cardiac abnormalities or increased arterial oxygen desaturation are uncovered.

\section{Therapy of COPD}

At present, smoking cessation is the only intervention that has been conclusively shown to slow the progression of COPD $^{14,15}$ and should be implemented in all patients as early as possible, ${ }^{1}$ but a recent systematic review of studies in mild-to-moderate COPD (patients with $\mathrm{FEV}_{1} \geq 50 \%$ predicted) has shown that, in addition to smoking cessation, pharmacologic and nonpharmacologic treatment initiated in the early stages of the disease can also have a beneficial effect on disease symptoms and prognosis. ${ }^{101}$ Nonetheless, relieving symptoms and improving exercise tolerance are increasingly recognized as important goals of treatment for COPD, and benefits can be achieved using both pharmacologic and nonpharmacologic interventions. ${ }^{1,16,17}$

\section{Pharmacologic therapy}

Maintenance therapy of COPD with long-acting bronchodilators can significantly reduce the impact of the disease. ${ }^{102-104} \mathrm{In}$ patients with COPD and persistent activity-related dyspnea, it is important to first achieve sustained bronchodilation and lung deflation to reduce dyspnea, allowing patients to engage more in activities of daily living.

The GOLD guidelines ${ }^{1}$ assign patients with COPD to four separate groups (A-D) on the basis of combined assessment of airflow limitation, symptoms, and exacerbation risk, and provide recommendations for initial pharmacologic treatment based on these groups (Table 1). To date, there is insufficient evidence for recommendations for the pharmacologic treatment of patients with few symptoms and at low risk (group A).

For patients with spirometrically confirmed COPD who report persistent activity-related dyspnea, the initial goal is to reduce EFL in order to address lung hyperinflation and dyspnea. By virtue of their ability to relax airway smooth muscle tone, all classes of bronchodilators enhance lung emptying and increase inspiratory capacity. ${ }^{27,105-107}$ The majority of clinical studies of bronchodilators for COPD have been conducted in patients with more severe airflow limitation (GOLD 3 and GOLD 4, groups C and D), and their efficacy in improving lung function, symptoms, and exercise tolerance is well established in these patients. ${ }^{27-29,76-78,106}$ However, there is an increasing body of evidence on the pharmacological treatment of patients with mild-to-moderate COPD that supports treatment at the early stages of the disease. ${ }^{108,109}$ 
Table I Global initiative for chronic Obstructive Lung Disease recommendations for initial pharmacologic management of chronic obstructive pulmonary disease (COPD)

\begin{tabular}{|c|c|c|c|}
\hline Patient group & Recommended First Choice & Alternative Choice & Other possible treatments** \\
\hline \multicolumn{4}{|c|}{ Initial Pharmacologic Management of COPD* } \\
\hline A & $\begin{array}{l}\text { Short-acting anticholinergic prn } \\
\text { or } \\
\text { Short-acting beta }{ }_{2} \text {-agonist prn }\end{array}$ & $\begin{array}{l}\text { Long-acting anticholinergic } \\
\text { or } \\
\text { Long-acting beta }{ }_{2} \text {-agonist } \\
\text { or } \\
\text { Short-acting beta }{ }_{2} \text {-agonist and short-acting } \\
\text { anticholinergic }\end{array}$ & Theophylline \\
\hline B & $\begin{array}{l}\text { Long-acting anticholinergic } \\
\text { or } \\
\text { Long-acting beta }{ }_{2} \text {-agonist }\end{array}$ & $\begin{array}{l}\text { Long acting anticholinergic and long-acting } \\
\text { beta }_{2} \text {-agonist }\end{array}$ & $\begin{array}{l}\text { Short-acting beta }{ }_{2} \text {-agonist } \\
\text { andlor } \\
\text { Short-acting anticholinergic } \\
\text { Theophylline }\end{array}$ \\
\hline C & $\begin{array}{l}\text { Inhaled corticosteroid + long-acting } \\
\text { beta }_{2} \text {-agonist } \\
\text { or } \\
\text { Long-acting anticholinergic }\end{array}$ & $\begin{array}{l}\text { Long-acting anticholinergic and long-acting } \\
\text { beta }_{2} \text {-agonist } \\
\text { or } \\
\text { Long-acting anticholinergic and } \\
\text { phosphodiesterase- } 4 \text { inhibitor } \\
\text { or } \\
\text { Long-acting beta }{ }_{2} \text {-agonist and } \\
\text { phosphodiesterase- } 4 \text { inhibitor }\end{array}$ & $\begin{array}{l}\text { Short-acting beta }{ }_{2} \text {-agonist } \\
\text { andlor } \\
\text { Short-acting anticholinergic } \\
\text { Theophylline }\end{array}$ \\
\hline D & $\begin{array}{l}\text { Inhaled corticosteroid + long-acting } \\
\text { beta }_{2} \text {-agonist } \\
\text { and/or } \\
\text { Long-acting anticholinergic }\end{array}$ & $\begin{array}{l}\text { Inhaled corticosteroid + long-acting beta }{ }_{2} \text {-agonist } \\
\text { and long-acting anticholinergic } \\
\text { or } \\
\text { Inhaled corticosteroid + long-acting beta } 2 \text {-agonist } \\
\text { and phosphodiesterase-4 inhibitor } \\
\text { or } \\
\text { Long-acting anticholinergic and long-acting } \\
\text { beta }{ }_{2} \text {-agonist } \\
\text { or } \\
\text { Long-acting anticholinergic and } \\
\text { phosphodiesterase-4 inhibitor }\end{array}$ & $\begin{array}{l}\text { Carbocysteine } \\
\text { Short-acting beta } 2 \text {-agonist } \\
\text { andlor } \\
\text { Short-acting anticholinergic } \\
\text { Theophylline }\end{array}$ \\
\hline
\end{tabular}

Notes: *Medications in each box are mentioned in alphabetical order, and therefore not necessarily in order of preference; $* * m e d i c a t i o n s$ in this column can be used alone or in combination with other options in the Recommended First Choice and Alternative Choice columns.

Reproduced with permission from Global Strategy for Diagnosis, Management, and Prevention of COPD. Global initiative for chronic Obstructive Lung Disease (GOLD); updated 2014. Available from: http://www.goldcopd.org/. Accessed January 27, 20I4.'

Abbreviation: prn, pro re nata.

The effects of short-acting bronchodilators on exercise tolerance have been examined in symptomatic patients with mild airflow limitation (equivalent to group B). ${ }^{45,110}$ Despite modest improvements in airway function, operating lung volumes, and dyspnea intensity, short-acting agents yield no significant improvements in exercise endurance. Correspondingly, the GOLD guidelines ${ }^{1}$ view long-acting bronchodilators as superior to short-acting bronchodilators for patients in group B; however, this recommendation is based on expert consensus opinion rather than evidence from clinical trials.

The results from a study by Casaburi et al; unpublished data, 2014 ClinicalTrials.gov identifier: NCT01072396) indicated that tiotropium significantly improved exercise duration compared with placebo in patients with GOLD 2 COPD (although not in patients with GOLD 1 COPD), and this improvement was associated with significant improvements in dynamic lung hyperinflation. This study has the largest cohort to date on which the effects of bronchodilator treatment in patients with mild-to-moderate COPD (48 patients with GOLD 1 COPD and 78 patients with GOLD 2 COPD) have been assessed. Further investigations are clearly warranted into the benefits of bronchodilator treatment in mild COPD and the long-term effects of bronchodilators on physical activity.

\section{Pulmonary rehabilitation}

Every effort should be made to inform patients with COPD about the benefits of physical activity due to its correlation with all-cause mortality. Exercise training improves skeletal muscle function to reduce ventilatory requirements, leading to reductions in dynamic hyperinflation and exertional dyspnea. ${ }^{20}$ Thus, exercise training may interrupt the cycle of decline leading to inactivity. Exercise training serves as the cornerstone of PR, which also includes patient assessment, self-management education, nutritional intervention, 
and psychosocial support. ${ }^{111}$ Multiple guidelines for COPD recommend PR for all symptomatic patients, regardless of disease severity. ${ }^{1,17,20}$ These recommendations are based on evidence for improvement in dyspnea, quality of life, exercise endurance, and functional capacity, for which PR is stronger than almost any other therapy in COPD; ${ }^{20} \mathrm{PR}$ has also been shown to have a beneficial effect in reducing levels of anxiety and depression, which are common comorbidities also seen in mild-to-moderate COPD. ${ }^{1,112,113}$

Despite these recommendations, there have been few studies to evaluate the benefits of PR in patients with mild COPD. The findings of an early systematic review suggested that physical activity can significantly improve physical fitness in patients with mild-to-moderate COPD. ${ }^{114}$ However, no improvements to health-related quality of life or dyspnea were reported. A more recent systematic review indicated there were significant, positive effects of PR on exercise capacity and quality of life in patients with mild COPD. ${ }^{115}$ Nevertheless, the impact of PR on health care resource use and lung function in patients was inconclusive. Together, these findings suggest that patients with mild COPD may benefit from PR programs as a part of their disease management, but further prospective studies are required.

\section{Conclusion}

Accumulating evidence suggests that pathological changes leading to exercise limitation are present even in symptomatic patients with mild COPD, and such patients show evidence of impairment in the form of increased exertional dyspnea and leg discomfort. ${ }^{1,10,11,18}$ Although the mechanisms of this impairment are multifactorial, abnormal ventilatory mechanics linked to EFL, lung hyperinflation, ventilatory inefficiency, and exertional dyspnea are central to the process. ${ }^{5,10-12,18,19}$ Patients adapt to exertional dyspnea by decreasing physical activity, beginning with nonessential leisure activities, and progressing to include basic activities of daily living. This reduction in physical activity leads to deconditioning, which not only worsens dyspnea, but also negatively affects health status and prognosis. ${ }^{13}$

Pulmonologists have a range of tools, including the 6MWT, ISWT, ESWT, laboratory-based tests including the CWR test, and physical activity assessments (eg, questionnaires ${ }^{80,83,86,116}$ and pedometers and accelerometers ${ }^{67,68,71-73}$ ) by which to measure levels of physical activity in symptomatic mild COPD

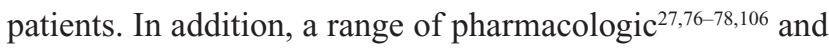
nonpharmacologic (smoking cessation, exercise training, and PR) treatments are available to manage COPD, ${ }^{1,16,17}$ although their potential benefits in mild disease are inconclusive. This review highlights recent evidence that exercise intolerance and activity limitation are apparent even in mild disease, ${ }^{10,11,18}$ with the reasonable hope that early intervention can help reduce disease progression in these patients, thereby reducing morbidity and mortality and, consequently, the need for hospitalizations and associated health care costs. Additional prospective clinical trials are urgently needed to determine if earlier introduction of pharmacotherapy is effective in patients with mild COPD.

\section{Acknowledgments}

The authors meet the criteria for authorship as recommended by the International Committee of Medical Journal Editors (ICMJE), were fully responsible for all content and editorial decisions, and were involved at all stages of manuscript development. This work was supported by Boehringer Ingelheim Pharmaceuticals, Inc. (BIPI) and Pfizer Inc. Writing, editorial support, and formatting assistance was provided by Gill Sperrin CBiol MSB CMPP and Neil M Thomas $\mathrm{PhD}$, of Envision, which was contracted and compensated by BIPI and Pfizer Inc. for these services.

\section{Disclosure}

Dr O’Donnell has received grants and personal fees from Boehringer Ingelheim, Pfizer, and GlaxoSmithKline, and personal fees from AstraZeneca. Dr Gebke has received personal fees from Pfizer and Boehringer Ingelheim. The authors received no compensation related to the development of the manuscript. The authors report no other conflicts of interest in this work.

\section{References}

1. Global Strategy for Diagnosis, Management, and Prevention of COPD Global initiative for chronic Obstructive Lung Disease (GOLD); updated 2014. Available from: http://www.goldcopd.org/. Accessed January 27, 2014.

2. Morbidity and Mortality: 2009 Chart Book on Cardiovascular, Lung, and Blood Diseases. Bethesda, MD: National Heart, Lung, and Blood Institute; 2009. Available from: http://www.nhlbi.nih.gov/resources/ docs/2009_ChartBook.pdf. Accessed January 27, 2014.

3. Mapel DW, Dalal AA, Blanchette CM, Petersen H, Ferguson GT. Severity of COPD at initial spirometry-confirmed diagnosis: data from medical charts and administrative claims. Int J Chron Obstruct Pulmon Dis. 2011;6:573-581.

4. Bednarek M, Maciejewski J, Wozniak M, Kuca P, Zielinski J. Prevalence, severity and underdiagnosis of COPD in the primary care setting. Thorax 2008;63:402-407

5. Troosters T, Sciurba F, Battaglia S, et al. Physical inactivity in patients with COPD, a controlled multi-center pilot-study. Respir Med. 2010;104:1005-1011.

6. Garcia-Aymerich J, Lange P, Benet M, Schnohr P, Antó JM. Regular physical activity reduces hospital admission and mortality in chronic obstructive pulmonary disease: a population based cohort study. Thorax. 2006;61:772-778

7. ten Hacken NH. Physical inactivity and obesity: relation to asthma and chronic obstructive pulmonary disease? Proc Am Thorac Soc. 2009;6: 663-667. 
8. Bruunsgaard H. Physical activity and modulation of systemic low-level inflammation. J Leukoc Biol. 2005;78:819-835.

9. Garcia-Aymerich J, Farrero E, Félez MA, Izquierdo J, Marrades RM, Antó JM; Estudi del Factors de Risc d'Agudització de la MPOC investigators. Risk factors of readmission to hospital for a COPD exacerbation: a prospective study. Thorax. 2003;58:100-105.

10. Guenette JA, Jensen D, Webb KA, Ofir D, Raghavan N, O'Donnell DE. Sex differences in exertional dyspnea in patients with mild COPD: physiological mechanisms. Respir Physiol Neurobiol. 2011;177: $218-227$.

11. Ofir D, Laveneziana P, Webb KA, Lam YM, O'Donnell DE. Mechanisms of dyspnea during cycle exercise in symptomatic patients with GOLD stage I chronic obstructive pulmonary disease. Am J Respir Crit Care Med. 2008;177(6):622-629.

12. Díaz AA, Morales A, Díaz JC, et al. CT and physiologic determinants of dyspnea and exercise capacity during the six-minute walk test in mild COPD. Respir Med. 2013;107:570-579.

13. ZuWallack R. How are you doing? What are you doing? Differing perspectives in the assessment of individuals with COPD. COPD. 2007;4:293-297.

14. Anthonisen NR, Connett JE, Murray RP. Smoking and lung function of Lung Health Study participants after 11 years. Am J Respir Crit Care Med. 2002;166:675-679.

15. Anthonisen NR, Skeans MA, Wise RA, Manfreda J, Kanner RE, Connett JE. The effects of a smoking cessation intervention on 14.5-year mortality: a randomized clinical trial. Ann Intern Med. 2005;142:233-239.

16. Qaseem A, Wilt TJ, Weinberger SE, et al; American College of Physicians; American College of Chest Physicians; American Thoracic Society; European Respiratory Society. Diagnosis and management of stable chronic obstructive pulmonary disease: a clinical practice guideline update from the American College of Physicians, American College of Chest Physicians, American Thoracic Society, and European Respiratory Society. Ann Intern Med. 2011;155:179-191.

17. O'Donnell DE, Aaron S, Bourbeau J, et al. Canadian Thoracic Society recommendations for management of chronic obstructive pulmonary disease - 2007 update. Can Respir J. 2007;14 Suppl B:5B-32B.

18. Chin RC, Guenette JA, Cheng S, et al. Does the respiratory system limit exercise in mild chronic obstructive pulmonary disease? Am J Respir Crit Care Med. 2013;187:1315-1323.

19. McDonough JE, Yuan R, Suzuki M, et al. Small-airway obstruction and emphysema in chronic obstructive pulmonary disease. $N$ Engl J Med. 2011;365:1567-1575.

20. Nici L, Donner C, Wouters E, et al; ATS/ERS Pulmonary Rehabilitation Writing Committee. American Thoracic Society/European Respiratory Society statement on pulmonary rehabilitation. Am J Respir Crit Care Med. 2006;173:1390-1413.

21. Pitta F, Troosters T, Spruit MA, Probst VS, Decramer M, Gosselink R. Characteristics of physical activities in daily life in chronic obstructive pulmonary disease. Am J Respir Crit Care Med. 2005;171:972-977.

22. O'Donnell DE. Ventilatory limitations in chronic obstructive pulmonary disease. Med Sci Sports Exerc. 2001;33:S647-S655.

23. Saey D, Michaud A, Couillard A, et al. Contractile fatigue, muscle morphometry, and blood lactate in chronic obstructive pulmonary disease. Am J Respir Crit Care Med. 2005;171:1109-1115.

24. Man WD, Soliman MG, Gearing J, et al. Symptoms and quadriceps fatigability after walking and cycling in chronic obstructive pulmonary disease. Am J Respir Crit Care Med. 2003;168:562-567.

25. Palange P, Forte S, Onorati P, Manfredi F, Serra P, Carlone S. Ventilatory and metabolic adaptations to walking and cycling in patients with COPD. J Appl Physiol (1985). 2000;88:1715-1720.

26. Pepin V, Saey D, Whittom F, LeBlanc P, Maltais F. Walking versus cycling: sensitivity to bronchodilation in chronic obstructive pulmonary disease. Am J Respir Crit Care Med. 2005;172:1517-1522.

27. Maltais F, Hamilton A, Marciniuk D, et al. Improvements in symptomlimited exercise performance over $8 \mathrm{~h}$ with once-daily tiotropium in patients with COPD. Chest. 2005;128:1168-1178.
28. O'Donnell DE, Flüge T, Gerken F, et al. Effects of tiotropium on lung hyperinflation, dyspnoea and exercise tolerance in COPD. Eur Respir J. 2004;23:832-840.

29. O'Donnell DE, Voduc N, Fitzpatrick M, Webb KA. Effect of salmeterol on the ventilatory response to exercise in chronic obstructive pulmonary disease. Eur Respir J. 2004;24:86-94.

30. Matsuoka S, Washko GR, Dransfield MT, et al. Quantitative CT measurement of cross-sectional area of small pulmonary vessel in COPD: correlations with emphysema and airflow limitation. Acad Radiol. 2010;17:93-99.

31. Rambod M, Porszasz J, Make BJ, Crapo JD, Casaburi R. Six-minute walk distance predictors, including CT scan measures, in the COPDGene cohort. Chest. 2012;141:867-875.

32. Yuan R, Hogg JC, Paré PD, et al. Prediction of the rate of decline in FEV(1) in smokers using quantitative computed tomography. Thorax. 2009;64:944-949.

33. Deesomchok A, Webb KA, Forkert L, et al. Lung hyperinflation and its reversibility in patients with airway obstruction of varying severity. COPD. 2010;7:428-437.

34. Gagnon P, Guenette JA, Langer D, et al. Pathogenesis of hyperinflation in chronic obstructive pulmonary disease. Int J Chron Obstruct Pulmon Dis. 2014;9:187-201.

35. Hogg JC, Macklem PT, Thurlbeck WM. Site and nature of airway obstruction in chronic obstructive lung disease. NEngl J Med. 1968;278: $1355-1360$.

36. Hogg JC, Chu F, Utokaparch S, et al. The nature of small-airway obstruction in chronic obstructive pulmonary disease. $N$ Engl J Med. 2004;350:2645-2653.

37. Black LF, Hyatt RE, Stubbs SE. Mechanism of expiratory airflow limitation in chronic obstructive pulmonary disease associated with 1-antitrypsin deficiency. Am Rev Respir Dis. 1972;105:891-899.

38. Leaver DG, Tatterfield AE, Pride NB. Contributions of loss of lung recoil and of enhanced airways collapsibility to the airflow obstruction of chronic bronchitis and emphysema. J Clin Invest. 1973;52:2117-2128.

39. Mitzner W. Emphysema - a disease of small airways or lung parenchyma? N Engl J Med. 2011;365:1637-1639.

40. Corbin RP, Loveland M, Martin RR, Macklem PT. A four-year follow-up study of lung mechanics in smokers. Am Rev Respir Dis. 1979;120:293-304.

41. Barbera JA, Ramirez J, Roca J, Wagner PD, Sanchez-Lloret J, RodriguezRoisin R. Lung structure and gas exchange in mild chronic obstructive pulmonary disease. Am Rev Respir Dis. 1990;141:895-901.

42. Barberà JA, Riverola A, Roca J, et al. Pulmonary vascular abnormalities and ventilation-perfusion relationships in mild chronic obstructive pulmonary disease. Am J Respir Crit Care Med. 1994;149:423-429.

43. Rodríguez-Roisin R, Drakulovic M, Rodríguez DA, Roca J, Barberà JA, Wagner PD. Ventilation-perfusion imbalance and chronic obstructive pulmonary disease staging severity. J Appl Physiol (1985). 2009;106: 1902-1908.

44. Santos S, Peinado VI, Ramírez J, et al. Characterization of pulmonary vascular remodelling in smokers and patients with mild COPD. Eur Respir J. 2002;19:632-638.

45. O'Donnell DE, Laveneziana P, Ora J, Webb KA, Lam YM, Ofir D. Evaluation of acute bronchodilator reversibility in patients with symptoms of GOLD stage I COPD. Thorax. 2009;64:216-223.

46. O'Donnell DE, Maltais F, Porszasz J, et al. Lung function and exercise impairment in patients with GOLD stage I and II COPD. Am J Respir Crit Care Med. Conference, 18-23 May, 2012, San Francisco, California, USA. Abstr. No. D80.

47. Peinado VI, Barbera JA, Ramirez J, et al. Endothelial dysfunction in pulmonary arteries of patients with mild COPD. Am J Physiol. 1998;274:L908-L913.

48. Borg GA. Psychophysical bases of perceived exertion. Med Sci Sports Exerc.1982;14(5);377-381.

49. McParland C, Mink J, Gallagher CG. Respiratory adaptations to dead space loading during maximal incremental exercise. J Appl Physiol (1985). 1991;70:55-62. 
50. O'Donnell DE, Hong HH, Webb KA. Respiratory sensation during chest wall restriction and dead space loading in exercising men. $J$ Appl Physiol (1985). 2000;88:1859-1869.

51. Syabbalo NC, Zintel T, Watts R, Gallagher CG. Carotid chemoreceptors and respiratory adaptations to dead space loading during incremental exercise. J Appl Physiol (1985). 1993;75:1378-1384.

52. Brown SE, King RR, Temerlin SM, Stansbury DW, Mahutte CK, Light RW. Exercise performance with added dead space in chronic airflow obstruction. J Appl Physiol Respir Environ Exerc Physiol. 1984;56:1020-1026.

53. Barr RG, Bluemke DA, Ahmed FS, et al. Percent emphysema, airflow obstruction, and impaired left ventricular filling. $N$ Engl J Med. 2010;362:217-227.

54. Grau M, Barr RG, Lima JA, et al. Percent emphysema and right ventricular structure and function: the Multi-Ethnic Study of Atherosclerosis-Lung and Multi-Ethnic Study of Atherosclerosis-Right Ventricle Studies. Chest. 2013;144:136-144.

55. Malerba M, Ragnoli B, Salameh M, et al. Sub-clinical left ventricular diastolic dysfunction in early stage of chronic obstructive pulmonary disease. J Biol Regul Homeost Agents. 2011;25:443-451.

56. Mannino DM, Doherty DE, Sonia Buist A. Global Initiative on Obstructive Lung Disease (GOLD) classification of lung disease and mortality: findings from the Atherosclerosis Risk in Communities (ARIC) study. Respir Med. 2006;100:115-122.

57. Sabit R, Bolton CE, Fraser AG, et al. Sub-clinical left and right ventricular dysfunction in patients with COPD. Respir Med. 2010;104:1171-1178.

58. Smith BM, Kawut SM, Bluemke DA, et al. Pulmonary hyperinflation and left ventricular mass: the Multi-Ethnic Study of Atherosclerosis COPD Study. Circulation. 2013;127:1503-1511.

59. Thomashow MA, Shimbo D, Parikh MA, et al. Endothelial microparticles in mild chronic obstructive pulmonary disease and emphysema. The Multi-Ethnic Study of Atherosclerosis Chronic Obstructive Pulmonary Disease study. Am J Respir Crit Care Med. 2013;188:60-68.

60. Lange P, Marott JL, Vestbo J, et al. Prediction of the clinical course of chronic obstructive pulmonary disease, using the new GOLD classification: a study of the general population. Am J Respir Crit Care Med. 2012;186:975-981.

61. Roig M, Eng JJ, MacIntyre DL, Road JD, Reid WD. Deficits in muscle strength, mass, quality, and mobility in people with chronic obstructive pulmonary disease. J Cardiopulm Rehabil Prev. 2011;31:120-124.

62. Orozco-Levi M, Coronell C, Ramírez-Sarmiento A, et al. Injury of peripheral muscles in smokers with chronic obstructive pulmonary disease. Ultrastruct Pathol. 2012;36:228-238.

63. van den Borst B, Slot IG, Hellwig VA, et al. Loss of quadriceps muscle oxidative phenotype and decreased endurance in patients with mild-tomoderate COPD. J Appl Physiol (1985). 2013;114:1319-1328.

64. Clark CJ, Cochrane LM, Mackay E, Paton B. Skeletal muscle strength and endurance in patients with mild COPD and the effects of weight training. Eur Respir J. 2000;15:92-97.

65. Seymour JM, Spruit MA, Hopkinson NS, et al. The prevalence of quadriceps weakness in COPD and the relationship with disease severity. Eur Respir J. 2010;36:81-88.

66. Vogiatzis I, Zakynthinos S. The physiological basis of rehabilitation in chronic heart and lung disease. J Appl Physiol (1985). 2013;115: $16-21$.

67. Pitta F, Troosters T, Probst VS, Spruit MA, Decramer M, Gosselink R. Quantifying physical activity in daily life with questionnaires and motion sensors in COPD. Eur Respir J. 2006;27:1040-1055.

68. Moore R, Berlowitz D, Denehy L, Jackson B, McDonald CF. Comparison of pedometer and activity diary for measurement of physical activity in chronic obstructive pulmonary disease. J Cardiopulm Rehabil Prev. 2009;29:57-61.

69. Maltais F. Exercise and COPD: therapeutic responses, diseaserelated outcomes, and activity-promotion strategies. Phys Sportsmed. 2013;41:66-80.

70. Le Masurier GC, Tudor-Locke C. Comparison of pedometer and accelerometer accuracy under controlled conditions. Med Sci Sports Exerc. 2003;35:867-871.
71. Pitta F, Troosters T, Spruit MA, Decramer M, Gosselink R. Activity monitoring for assessment of physical activities in daily life in patients with chronic obstructive pulmonary disease. Arch Phys Med Rehabil. 2005;86:1979-1985.

72. Patel SA, Benzo RP, Slivka WA, Sciurba FC. Activity monitoring and energy expenditure in COPD patients: a validation study. COPD. 2007;4:107-112.

73. Watz H, Waschki B, Meyer T, Magnussen H. Physical activity in patients with COPD. Eur Respir J. 2009;33:262-272.

74. Waschki B, Kirsten A, Holz O, et al. Physical activity is the strongest predictor of all-cause mortality in patients with COPD: a prospective cohort study. Chest. 2011;140:331-342.

75. Lacasse Y, Martin S, Lasserson TJ, Goldstein RS. Meta-analysis of respiratory rehabilitation in chronic obstructive pulmonary disease. A Cochrane systematic review. Eura Medicophys. 2007; $43: 475-485$

76. Worth H, Förster K, Eriksson G, Nihlén U, Peterson S, Magnussen $\mathrm{H}$. Budesonide added to formoterol contributes to improved exercise tolerance in patients with COPD. Respir Med. 2010;104: $1450-1459$.

77. Maltais F, Celli B, Casaburi R, et al. Aclidinium bromide improves exercise endurance and lung hyperinflation in patients with moderate to severe COPD. Respir Med. 2011;105:580-587.

78. O'Donnell DE, Casaburi R, Vincken W, et al. Effect of indacaterol on exercise endurance and lung hyperinflation in COPD. Respir Med. 2011;105:1030-1036.

79. Borel B, Provencher S, Saey D, Maltais F. Responsiveness of various exercise-testing protocols to therapeutic interventions in COPD. Pulm Med. 2013;2013:410748.

80. Belfer MH, Reardon JZ. Improving exercise tolerance and quality of life in patients with chronic obstructive pulmonary disease. JAm Osteopath Assoc. 2009;109:268-278.

81. Garrod R, Bestall JC, Paul EA, Wedzicha JA, Jones PW. Development and validation of a standardized measure of activity of daily living in patients with severe COPD: the London Chest Activity of Daily Living scale (LCADL). Respir Med. 2000;94:589-596.

82. Janaudis-Ferreira T, Beauchamp MK, Robles PG, Goldstein RS, Brooks D. Measurement of activities of daily living in patients with COPD: a systematic review. Chest. 2014;145:253-271.

83. Doherty DE, Belfer MH, Brunton SA, Fromer L, Morris CM, Snader TC. Chronic obstructive pulmonary disease: consensus recommendations for early diagnosis and treatment. J Fam Pract Clinical update. 2006;55(Suppl):S1-S8.

84. Jones PW, Harding G, Berry P, Wiklund I, Chen WH, Kline Leidy N. Development and first validation of the COPD Assessment Test. Eur Respir J. 2009;34:648-654.

85. Jones PW, Brusselle G, Dal Negro RW, et al. Properties of the COPD assessment test in a cross-sectional European study. Eur Respir J. 2011;38:29-35.

86. Powrie DJ. The BODE index: a new grading system in COPD. Thorax. 2004;59:427.

87. Celli BR, Cote CG, Marin JM, et al. The body-mass index, airflow obstruction, dyspnea, and exercise capacity index in chronic obstructive pulmonary disease. N Engl J Med. 2004;350:1005-1012.

88. ATS Committee on Proficiency Standards for Clinical Pulmonary Function Laboratories. ATS statement: guidelines for the six-minute walk test. Am J Respir Crit Care Med. 2002;166:111-117.

89. Solway S, Brooks D, Lacasse Y, Thomas S. A qualitative systematic overview of the measurement properties of functional walk tests used in the cardiorespiratory domain. Chest. 2001;119:256-270.

90. Golpe R, Pérez-de-Llano LA, Méndez-Marote L, Veres-Racamonde A. Prognostic value of walk distance, work, oxygen saturation, and dyspnea during 6-minute walk test in COPD patients. Respir Care. 2013;58:1329-1334.

91. Casanova C, Cote C, Marin JM, et al. Distance and oxygen desaturation during the 6-min walk test as predictors of long-term mortality in patients with COPD. Chest. 2008;134:746-752. 
92. Pinto-Plata VM, Cote C, Cabral H, Taylor J, Celli BR. The 6-min walk distance: change over time and value as a predictor of survival in severe COPD. Eur Respir J. 2004;23:28-33.

93. Ilgin D, Ozalevli S, Kilinc O, Sevinc C, Cimrin AH, Ucan ES. Gait speed as a functional capacity indicator in patients with chronic obstructive pulmonary disease. Ann Thorac Med. 2011;6: 141-146.

94. Morgan MD, Singh SJ. Assessing the exercise response to a bronchodilator in COPD: time to get off your bike? Thorax. 2007;62: 281-283.

95. Singh SJ, Morgan MD, Scott S, Walters D, Hardman AE. Development of a shuttle walking test of disability in patients with chronic airways obstruction. Thorax. 1992;47:1019-1024.

96. Revill SM, Morgan MD, Singh SJ, Williams J, Hardman AE. The endurance shuttle walk: a new field test for the assessment of endurance capacity in chronic obstructive pulmonary disease. Thorax. 1999;54: 213-222.

97. Pepin V, Brodeur J, Lacasse Y, et al. Six-minute walking versus shuttle walking: responsiveness to bronchodilation in chronic obstructive pulmonary disease. Thorax. 2007;62:291-298.

98. Brouillard C, Pepin V, Milot J, Lacasse Y, Maltais F. Endurance shuttle walking test: responsiveness to salmeterol in COPD. Eur Respir J. 2008;31:579-584.

99. Boer LM, Asijee GM, van Schayck OC, Schermer TR. How do dyspnoea scales compare with measurement of functional capacity in patients with COPD and at risk of COPD? Prim Care Respir J. 2012;21: 202-207.

100. O'Donnell DE, Maltais F, Porszasz J, et al. The continuum of physiological impairment during treadmill walking in patients with mild-to-moderate COPD: patient characterization phase of a randomized clinical trial. PLoS ONE. 2014;9(5):e96574.

101. Maltais F, Dennis N, Chan CK. Rationale for earlier treatment in COPD: a systematic review of published literature in mild-to-moderate COPD. COPD. 2013;10:79-103.

102. Calverley PM, Anderson JA, Celli B, et al. Salmeterol and fluticasone propionate and survival in chronic obstructive pulmonary disease. N Engl J Med. 2007;356:775-789.

103. Decramer M, Celli B, Kesten S, Lystig T, Mehra S, Tashkin DP; UPLIFT investigators. Effect of tiotropium on outcomes in patients with moderate chronic obstructive pulmonary disease (UPLIFT): a prespecified subgroup analysis of a randomised controlled trial. Lancet. 2009;374:1171-1178.
104. Jenkins CR, Jones PW, Calverley PM, et al. Efficacy of salmeterol/ fluticasone propionate by GOLD stage of chronic obstructive pulmonary disease: analysis from the randomised, placebo-controlled TORCH study. Respir Res. 2009;10:59.

105. Belman MJ, Botnick WC, Shin JW. Inhaled bronchodilators reduce dynamic hyperinflation during exercise in patients with chronic obstructive pulmonary disease. Am J Respir Crit Care Med. 1996;153: 967-975.

106. O'Donnell DE, Sciurba F, Celli B, et al. Effect of fluticasone propionate/salmeterol on lung hyperinflation and exercise endurance in COPD. Chest. 2006;130:647-656.

107. Peters MM, Webb KA, O'Donnell DE. Combined physiological effects of bronchodilators and hyperoxia on exertional dyspnoea in normoxic COPD. Thorax. 2006;61:559-567.

108. Raghavan N, Guenette JA, O’Donnell DE. The role of pharmacotherapy in mild to moderate chronic obstructive pulmonary disease. Ther $A d v$ Respir Dis. 2011;5:245-254.

109. Ferguson GT. Maintenance pharmacotherapy of mild and moderate COPD: what is the evidence? Respir Med. 2011;105:1268-1274.

110. Gagnon P, Saey D, Provencher S, et al. Walking exercise response to bronchodilation in mild COPD: a randomized trial. Respir Med. 2012;106:1695-1705.

111. Nici L, Lareau S, ZuWallack R. Pulmonary rehabilitation in the treatment of chronic obstructive pulmonary disease. Am Fam Physician. 2010;82:655-660.

112. Tselebis A, Bratis D, Pachi A, et al. A pulmonary rehabilitation program reduces levels of anxiety and depression in COPD patients. Multidiscip Respir Med. 2013;8:41.

113. Bratås O, Espnes GA, Rannestad T, Walstad R. Pulmonary rehabilitation reduces depression and enhances health-related quality of life in COPD patients - especially in patients with mild or moderate disease. Chron Respir Dis. 2010;7:229-237.

114. Chavannes N, Vollenberg JJ, van Schayck CP, Wouters EF. Effects of physical activity in mild to moderate COPD: a systematic review. $\mathrm{Br}$ J Gen Pract. 2002;52:574-578.

115. Jácome CI, Marques AS. Pulmonary rehabilitation for mild chronic obstructive pulmonary disease: A systematic review. Respir Care. 2014 Apr;59(4):588-594.

116. Martinez FJ, Raczek AE, Seifer FD, et al; COPD-PS Clinician Working Group. Development and initial validation of a self-scored COPD Population Screener Questionnaire (COPD-PS). COPD. 2008;5: 85-95.
International Journal of COPD

\section{Publish your work in this journal}

The International Journal of COPD is an international, peer-reviewed journal of therapeutics and pharmacology focusing on concise rapid reporting of clinical studies and reviews in COPD. Special focus is given to the pathophysiological processes underlying the disease, intervention programs, patient focused education, and self management protocols.

\section{Dovepress}

This journal is indexed on PubMed Central, MedLine and CAS. The manuscript management system is completely online and includes a very quick and fair peer-review system, which is all easy to use. Visit $\mathrm{http}: / /$ www.dovepress.com/testimonials.php to read real quotes from published authors. 